\title{
Preliminary Analysis of Hydrogen Production Integrated with Proton Exchange Membrane Fuel Cell
}

\author{
Lida Simasatitkul ${ }^{1, *}$, Suksun Amornraksa ${ }^{2}$, Natcha Wangprasert, and Thanaporn Wongjirasavat ${ }^{1}$ \\ ${ }^{1}$ Department of Industrial Chemistry, Faculty of Applied Science, King Mongkut's University of Technology North Bangkok, \\ Bangkok, Thailand \\ ${ }^{2}$ The Sirindhorn International Thai-German Graduate School of Engineering (TGGS) King Mongkut's University of Technology \\ North Bangkok, Bangkok, Thailand
}

\begin{abstract}
Proton exchange membrane fuel cell (PEMFC) is an interesting option for electricity generation. However, the usage of pure hydrogen feeding to PEMFC faces many problems such as high price and gas storage capacity. On-board fuel processor integrated with PEMFC is therefore a more preferable option. Two hydrogen production processes from crude ethanol feed, a by-product of fermentation of corn stover, integrated with PEMFC were developed and proposed. They are steam reforming (SR) process integrated with PEMFC and steam reforming process coupled with a CO preferential oxidation (COPROX) reactor with PEMFC. The results showed that the optimal operating conditions for both processes were similar i.e. S/F ratio of 9 , WGS reactor temperature of $250^{\circ} \mathrm{C}$ and membrane area of $0.6 \mathrm{~m}^{2}$. However, the optimal SR temperature of both processes were different i.e. $500^{\circ} \mathrm{C}$ and $460^{\circ} \mathrm{C}$. Both processes produced pure hydrogen gas at $0.53 \mathrm{~mol} / \mathrm{s}$. The energy requirement of the SR process alone was higher than SR process coupled with a COPROX about $0.19 \mathrm{MW}$. The produced hydrogen gas entered PEMFC at current density of $1.1 \mathrm{~A} \mathrm{~cm}^{-2}$, generating the power at of $0.44 \mathrm{~W} \mathrm{~cm}^{-2}$.
\end{abstract}

\section{Introduction}

Increasing energy demand over the past decades leads to lack of energy resources and high price. The electricity generation from coal is limited due to effect on the environment such as greenhouse gas effect and emission of particle matters. To overcome such a difficulty, alternative energy is developed to replace fossil energy. Fuel cell technology is an interesting option for the future as it generates electricity from electrochemical reaction of hydrogen and oxygen. This technology is more effective and environmentally friendly than conventional methods. Among several types of fuel cell, proton exchange membrane fuel cell (PEMFC) is preferred due to light weight and low operating temperature. So it is suitable for household, portable power application and electronic device [1].

Hydrogen is a clean energy. It is used as raw material feeding to fuel cell directly. However, the usage of pure hydrogen feeding to PEMFC faces many problems such as high price and gas storage capacity. Thus, on-board fuel processor integrated with PEMFC is preferred. Hydrogen production technology such as water electrolysis, reforming from natural gas [2] and biomass gasification has been researched. Among these, steam reforming is an attractive process. Because it has economical advantage for large capacity, effective for producing high $\mathrm{H}_{2} / \mathrm{CO}$ ratio and high performance of 70$82 \%$.

Presently, steam reforming, partial oxidation and autothermal reforming are considered a high potential method for hydrogen production. Typically, hydrogen is produced from steam reforming of natural gas. But it is non-renewable energy. Many researchers focus on the use of renewable resources for hydrogen production such as biomass, bioethanol, biomethane, bio-oil and crude glycerol [3]. The main reason is that they are abundant feedstock and inexpensive. For example, ethanol reforming is a promising process to produce hydrogen. Lui et al., [4] analyzed hydrogen production from steam reforming, partial oxidation and autothermal reforming. Temperature of $900 \mathrm{~K}$ promoted hydrogen yield but not for methane. Additional oxygen resulted in heat cycle for neutral-thermal condition. Authayanun et al., [3] proposed hydrogen reforming from bio-oil. They found that increasing $\mathrm{S} / \mathrm{C}$ ratio and $\mathrm{O} / \mathrm{C}$ ratio prevented coke formation. The temperature of $700^{\circ} \mathrm{C}$ resulted in high hydrogen yield of $67 \%$. This process required high energy for steam generation.

To reduce the energy consumption, Wiranarongkorn et al., [5] proposed tri-reforming of bio-oil. The optimal parameters were $\mathrm{S} / \mathrm{F}$ of 6 and temperature of $580^{\circ} \mathrm{C}$. This process reduced energy around $10 \%$ compared with conventional process. From the literatures, steam ethanol reforming resulted in high hydrogen yield product when compared with other renewable feeds such as glycerol and biogas [6]. However, few works concerned hydrogen production from bioethanol from fermentation broths. The ethanol recovery is complicated and low concentration of bioethanol is obtained. It can be converted to high valueadded product such as hydrogen.

\footnotetext{
* Corresponding author: lida.s@sci.kmutnb.ac.th
} 
Thus, this work focused on hydrogen production integrated with PEMFC for electricity generation. Steam reforming (SR) process integrated with PEMFC and steam reforming process coupled with a $\mathrm{CO}$ preferential oxidation (COPROX) reactor with PEMFC were proposed. The effect of parameters was determined in term of hydrogen yield and energy requirement. The suitable process was determined by comparing with the total energy requirement and power density.

\section{Methodology and modelling}

Mass balance and energy balance of the hydrogen production integrated PEMFC was performed by Aspen Plus. Soave Redlich-Kwong (SRK) was used to predict thermodynamic property and vapor-liquid equilibrium. Crude ethanol from fermentation of corn stover at 1 $\mathrm{mol} / \mathrm{s}$ was used as a basis according to Sengupta et al., [7]. Next, the two processes were developed based on thermodynamic equilibrium. Mathematical model of membrane separator and PEMFC were carried out in a calculator block that were inserted in form of Fortran code. Then parametric analysis was studied in terms of hydrogen yield.

\subsection{Reactor model}

A reactor model was calculated by minimizing Gibb free energy as shown in eq (1)-(3).

$$
\begin{gathered}
\min _{n_{i}}(G)_{T, P} \\
(G)_{T, P}=\sum_{i=1}^{C} G_{i}^{0}+R T \ln \frac{\hat{f_{i}}}{f_{i}^{0}} \\
\text { S.t. } \sum_{i=1} n_{i} a_{i k}-A_{k}=0
\end{gathered}
$$

Where $A_{k}$ is $C, H, O$ atoms in the feed stream.

\subsection{Membrane model}

Membrane was used for hydrogen purification before feeding to PEMFC. Parameters such as hydrogen partial pressure on the retentate, hydrogen partial pressure on the permeate, permeability value and membrane thickness were given according to Howard et al., [8]. The molar flux of hydrogen was shown in eq (4).

$$
N_{H_{2}}=\frac{k\left(P_{H_{2}, \text { ret }}^{2}-P_{H_{2}, \text { perm }}^{2}\right)}{X_{M}}
$$

Thus, the molar flow rate of hydrogen from membrane was shown in eq (5).

$$
M_{H_{2, \text { perm }}}=N_{H_{2}} \times A
$$

\subsection{PEMFC model}

Parameters of PEMFC model was given according to Wang et al., [9]. When hydrogen utilization was 0.88 $[10]$, the fuel utilization factor was 1.136. Open circuit voltage was shown in eq (6).

$E_{\text {OCV }}=1.229-8.5 \times 10^{-4}(T-298.15)+\frac{R T}{2 F} \ln \left[P_{H_{2}} P_{O_{2}}^{0.5}\right]$

Anode Surface Overpotential was shown in eq (7).

$$
n_{\text {anode }}=\frac{R T}{\alpha F} \sinh ^{-1}\left(\frac{i}{2 k_{e h} C_{H_{2}}}\right)
$$

Cathode Surface Overpotential was shown in eq (8).

$$
n_{\text {cathade }}=\frac{R T}{\alpha F} \ln \left(\frac{i}{i_{O C}}\right)
$$

Ohmic Voltage loss was shown in eq (9).

$$
n_{\text {ohmic }}=i R_{\text {ohmic }}
$$

Thus, cell voltage in PEMFC was shown in eq (10).

$$
E_{\text {cell }}=E_{\text {OCV }}-n_{\text {anode }}-n_{\text {cathode }}-n_{\text {Ohmic }}
$$

\section{Process description}

\subsection{SR process integrated with PEMFC}

Crude ethanol was fed to a filter (SEP) for solid separation. The products were Ethanol, $\mathrm{H}_{2} \mathrm{O}, \mathrm{CO}_{2}$, glucose, xylose and succinic acid. Then, they were preheated by steam and fed to the reformer (SR). The temperature was varied between $300-800^{\circ} \mathrm{C}$. Next, they were cooled down and sent to water gas shift reactor (WGS) operating at $250^{\circ} \mathrm{C}$. The gaseous products from the WGS containing hydrogen, $\mathrm{CO}$, and $\mathrm{CO}_{2}$ were sent to a gas compressor to increase pressure to $3 \mathrm{~atm}$. After that, a membrane was required for hydrogen purification. At the end, the obtained pure hydrogen and air were fed to PEMFC. The process was shown in Fig.1.

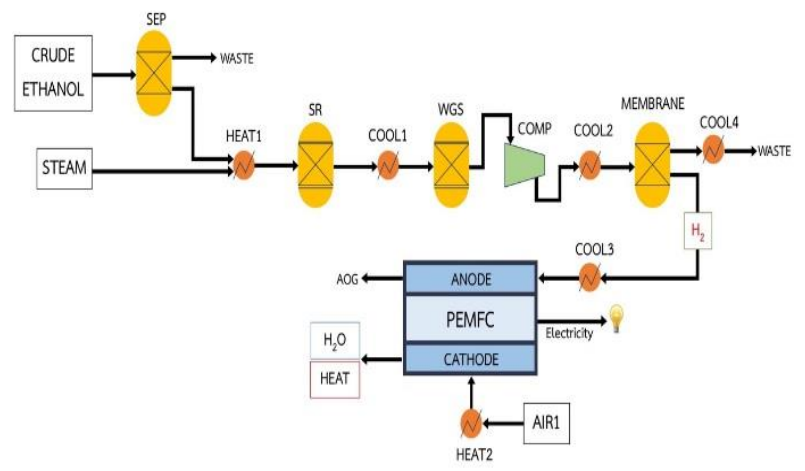

Fig. 1. SR process integrated with PEMFC 


\subsection{COPROX process integrated with PEMFC}

The operation of COPROX process was similar to SR process. However, the effluent stream from membrane separation was divided into two streams. One stream was sent to the PEMFC as usual while another stream was recirculated to a co-partial oxidation reactor (COPROX). The COPROX reactor was used to reduce amount of $\mathrm{CO}$ [10]. The partial oxidation reaction was exothermic so the heat released can be supplied to the steam reformer. This process was presented in Fig.2.

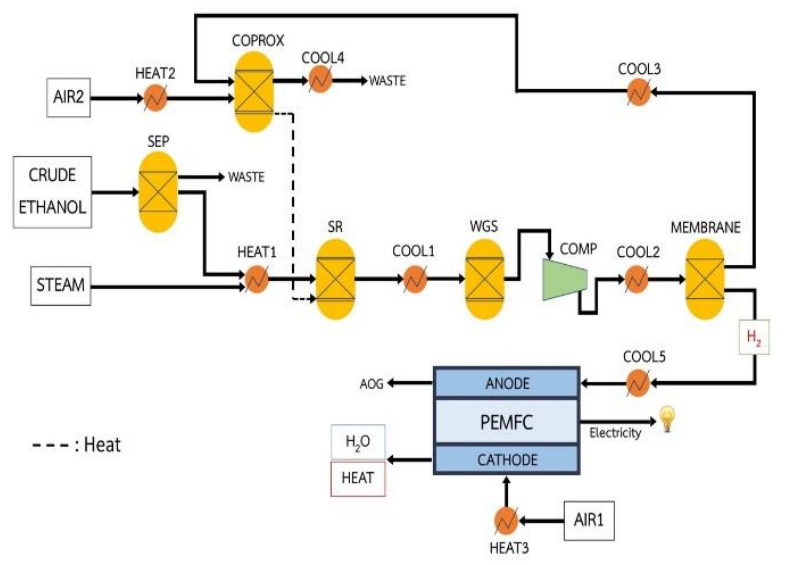

Fig. 2. COPROX process integrated with PEMFC

\section{Results and Discussions}

\subsection{Influence of temperature on SR reactor in SR process integrated with PEMFC}

The effect of temperature was studied in a range of $300-$ $800^{\circ} \mathrm{C}$ that was suitable for steam reforming. This work was performed based on thermodynamic analysis. All possible reactions such as steam reforming, dry reforming, water gas shift reaction, methanation, water gas reaction and boudouard reaction can be occurred. Fig. 3(a) - (c) showed that molar flow rate of hydrogen, $\mathrm{CO}$ and $\mathrm{CO}_{2}$ were increased with an increase in temperature. Steam reforming and dry reforming were promoted at high temperature because of endothermic reactions. However, the amount of hydrogen was decreased slightly at the temperature higher than $500^{\circ} \mathrm{C}$. This was because water gas shift reaction was also carried out in the SR. But it was the exothermic reaction that was flavoured at lower temperature. Thus, too high temperature led to the reversed reaction. Furthermore, increasing temperature hindered the boudouard reaction which was an exothermic reaction. As a result, carbon formation was not found. Considering the S/F ratio, increasing of S/F ratio led to increased molar flow rate of hydrogen. This was because steam reforming and dry reforming were shifted forward reaction. High S/F ratio promoted water gas reaction that was an endothermic reaction. Consequently, the coke was not formed. The $\mathrm{S} / \mathrm{F}$ ratio of 12 was found to be optimal as it resulted in the highest amount of hydrogen. Fig. 3(d) showed the molar flow rate of methane. Generally, it was decreased when the temperature and $\mathrm{S} / \mathrm{F}$ ratio increased. This was because of steam reforming and dry reforming of methane. So, it can be concluded that the optimal temperature was $500^{\circ} \mathrm{C}$ and the optimal $\mathrm{S} / \mathrm{F}$ ratio was 9 . The optimal condition was approached to the literature data [6].
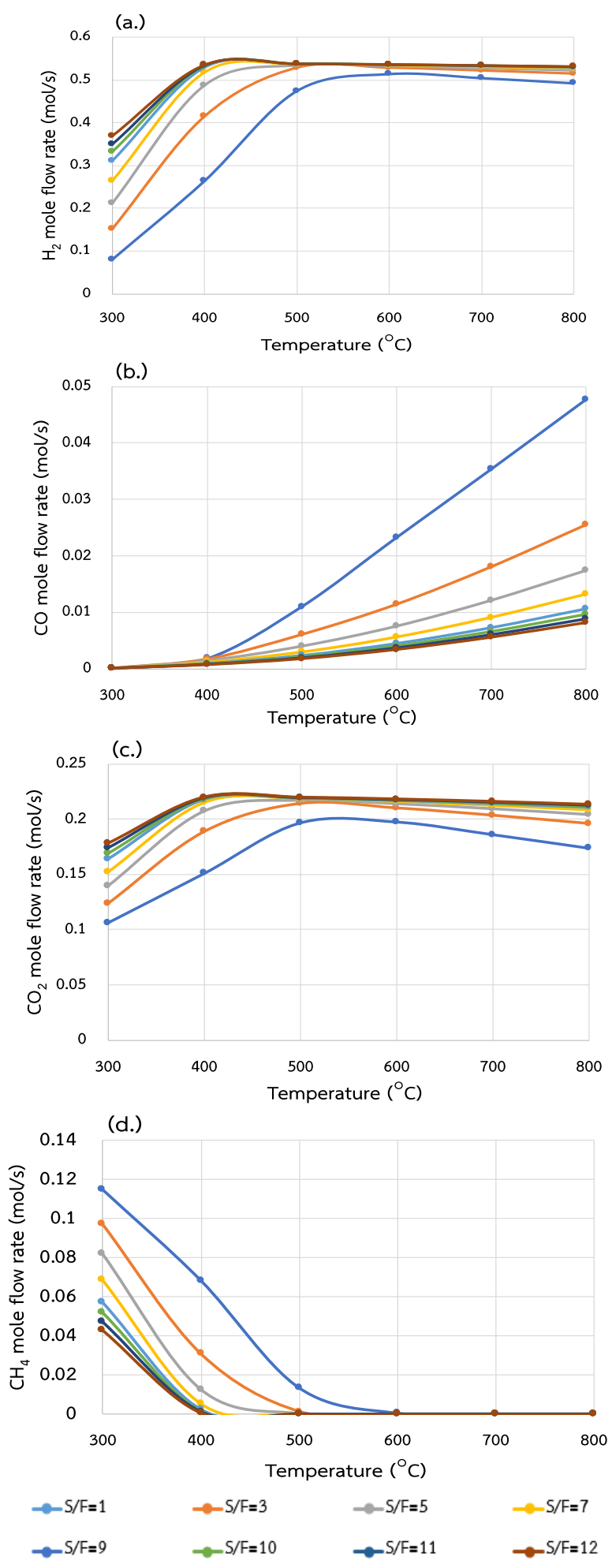

Fig. 3 The effect of temperature of SR reformer in SR process integrated with PEMFC on (a) molar flow rate of hydrogen (b) molar flow rate of $\mathrm{CO}$ (c) molar flow rate of $\mathrm{CO}_{2}$ (d) molar flow rate of $\mathrm{CH}_{4}$

\footnotetext{
* Corresponding author: lida.s@sci.kmutnb.ac.th
} 


\subsection{Influence of temperature on SR reactor in COPROX process integrated with PEMFC}

In this process, the gaseous products from membrane separation are $\mathrm{CO}$ and hydrogen. They were fed to COPROX reactor and mixed with air. The copreferential oxidation was carried out in the reactor. It has been known that this reaction was an exothermic reaction. So, the heat released from COPROX reactor can be supplied to the SR reactor. Temperature of COPROX reactor was fixed at $170^{\circ} \mathrm{C}$. Molar ratio of air to ethanol was fixed at 0.1 ; otherwise, the SR and WGS reactor cannot provide high hydrogen yield. From Fig. $4(a)-(d)$, the effect of temperature and S/F ratio were studied.

The results showed a similar trend as the SR process integrated with PEMFC but they cannot be operated at high temperature when the $\mathrm{S} / \mathrm{F}$ ratio was less than 1 . This was because the amount of synthesis gas produced was low. Consequently, supplying energy for the SR reactor was not enough to achieve required temperature. Thus, it should be operated at high S/F ratio. The results showed that the hydrogen molar flow rate was similar to the SR process integrated with PEMFC. No carbon was also detected in the product stream. So, the optimal temperature was $500^{\circ} \mathrm{C}$ and the optimal $\mathrm{S} / \mathrm{F}$ ratio was 9 .

\subsection{Influence of temperature on WGS reactor}

Fig. 5 showed the effect of operating temperature in WGS reactor of both processes. When the operating temperature of reformer was $500^{\circ} \mathrm{C}$. Methane was not taken into account for WGS reactor. Thus, methane reforming was not presented in the reactor. Molar flow rate of hydrogen and $\mathrm{CO}_{2}$ increased with an increase in temperature because the forward WGS was performed and $\mathrm{CO}$ was consumed completely. In addition, carbon formation was reduced at high temperature. Thus, no carbon was detected in the product stream before entering the membrane separation. This was because boudouard reaction and carbon formation were exothermic reaction. Thus, the reverse reactions of their reactions were formed. The optimal temperature was $250^{\circ} \mathrm{C}$.

\subsection{Comparison of energy requirement}

Table 1 compared the energy requirement of both processes. When $\mathrm{S} / \mathrm{F}$ ratio was 9 and amount of hydrogen was $0.54 \mathrm{~mol} / \mathrm{s}$. The results showed that energy requirement for operating of SR process integrated with PEMFC was lower than that of COPROX process integrated with PEMFC. This was because more energy was required to preheat air before feeding to COPROX reactor. In addition, the heat released from COPROX can be sent to SR reactor to meet the desired temperature. In addition, the COPROX process required less energy for cooling. (a.)

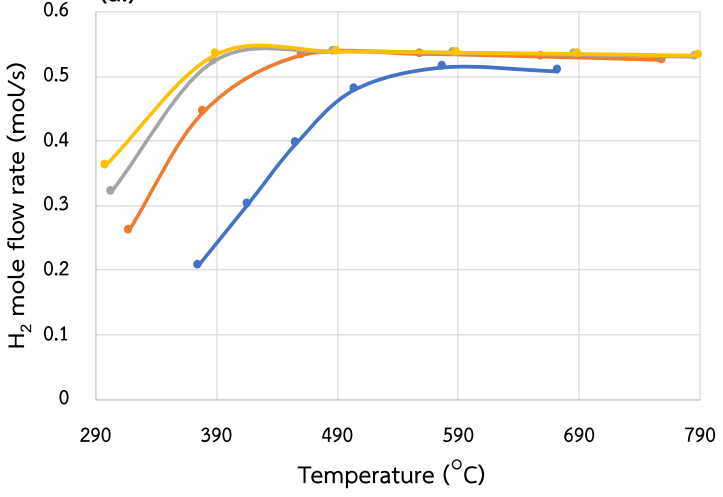

(b.)

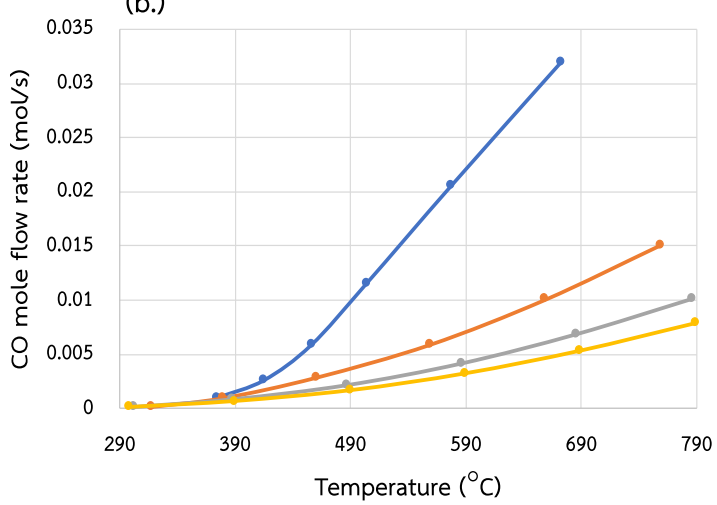

(c.)

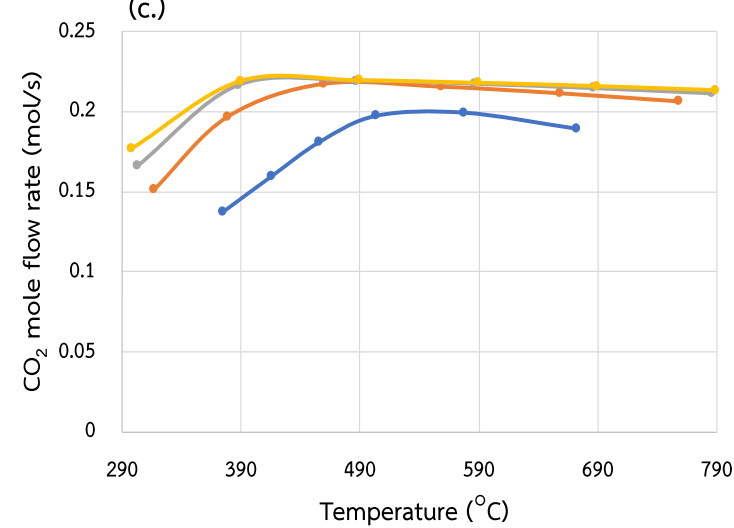

(d.)

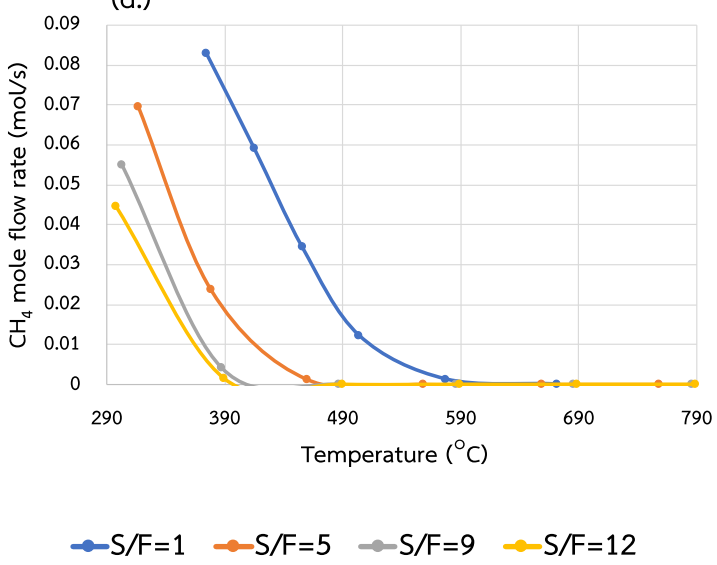

Fig. 4 The effect of temperature of SR reformer in COPROX process integrated with PEMFC on (a) molar flow rate of hydrogen (b) molar flow rate of $\mathrm{CO}$ (c) molar flow rate of $\mathrm{CO}_{2}$ (d) molar flow rate of $\mathrm{CH}_{4}$ 


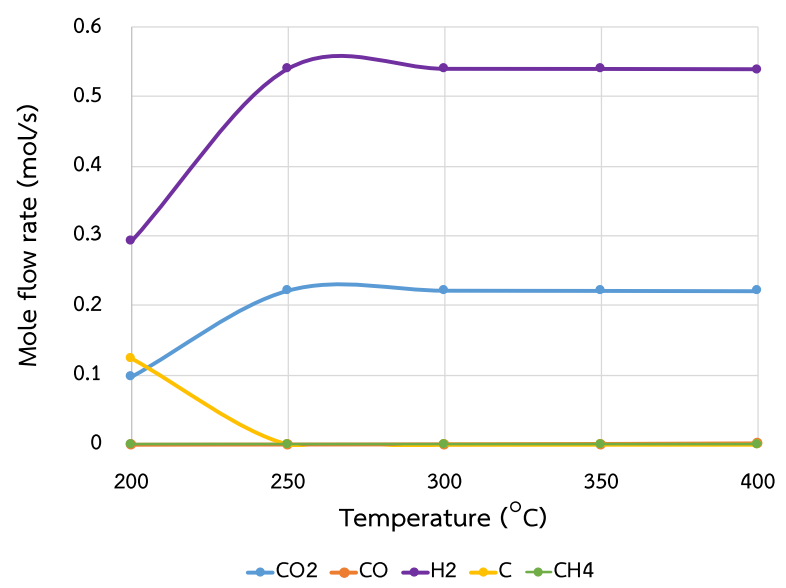

Fig. 5 The effect of temperature on WGS reactor when temperature of reformer is $500^{\circ} \mathrm{C}$

Table 1. Energy requirement for both processes

\begin{tabular}{|l|c|c|}
\hline \multirow{2}{*}{ Process } & \multicolumn{2}{|c|}{ Energy (MW) } \\
\cline { 2 - 3 } & Heating & Cooling \\
\hline SR process integrated with PEMFC & 1.41 & 1.08 \\
\hline $\begin{array}{l}\text { COPROX process integrated with } \\
\text { PEMFC }\end{array}$ & 1.60 & 1.07 \\
\hline
\end{tabular}

\subsection{Polarization curve of PEMFC}

Amount of hydrogen feeding to PEMFC was $0.53 \mathrm{~mol} / \mathrm{s}$ for both processes. The simulation result showed a good agreement with experimental data [9] at $80^{\circ} \mathrm{C}$ and $3 \mathrm{~atm}$. From Fig.6, voltage was decreased with an increase in current density. The polarization curve was divided into two zones: activation loss zone and ohmic loss zone. In term of power density, increasing current density resulted in high power density. However, an opposite trend was observed when the maximum current density was reached. The maximum power density was 0.44 $\mathrm{W} / \mathrm{cm}^{2}$.

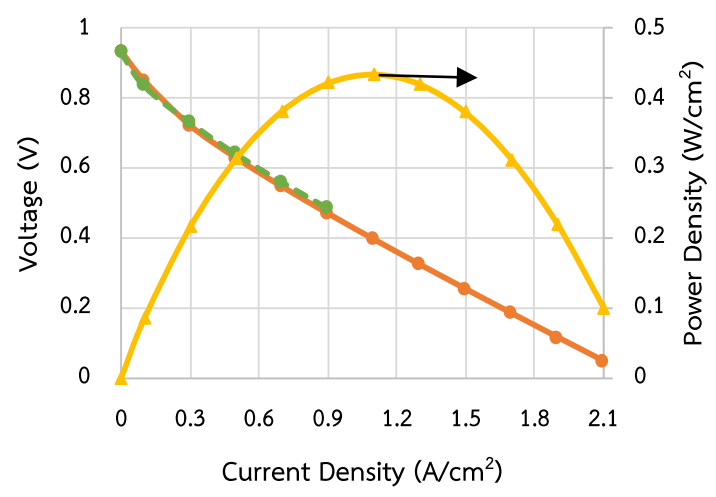

$-\mathrm{I}-\mathrm{V}$ curve (this work) $-\mathrm{IV}$ curve (Bhatia) $\longrightarrow \mathrm{IP}$ curve (this work)

Fig. 6. Polarization curve of both processes

\section{Conclusion}

The preliminary analysis of hydrogen production integrated PEMFC such as SR process integrated with PEMFC and COPROX process integrated with PEMFC was investigated. The optimal condition of both processes was $\mathrm{S} / \mathrm{F}$ ratio of 9 , SR temperature of $500^{\circ} \mathrm{C}$, WGS temperature of $250^{\circ} \mathrm{C}$, membrane area of $0.6 \mathrm{~m}^{2}$. The purity of hydrogen was 0.99 for the requirement for feedstock of PEMFC. The SR process integrated PEMFC was preferred because lower energy requirement for heating.

This research was funded by King Mongkut's University of Technology North Bangkok, Contract no. KMUNTB-GOV-58-40.

\section{References}

1. J.H. Wee, Renew Sust Energ Rev. 11, 1720 - 1738 (2007)

2. D.K. Lee, K.Y. Koo, D.J. Seo, W.L. Yoon. Renew Energ. 42, 234-242 (2012)

3. S. Authayanun, P. Aunsup, Y. Patcharavorachot, A. Arpornwichanop, Energ. Convers Manage 86, 60-69 (2014).

4. S. Liu, K. Zhang, L. Fang, Y. Li, Energy \&. Fuels. 22, 1365- 1370 (2008)

5. K. Wiranarongkorn, S. Authayanan, Int J Hydrogen Energy. 41, 8370-8379 (2016)

6. D. Seabea, A. Authayanun, Y. Patcharavorachot, W. Paengjuntuek, A. Arpornwichanop, Energy. 51, 305-313 (2013)

7. D. Sengupta, R.W. Pike. Boca Raton, Fla : CRC Press, 1st Edition (2017).

8. B.H. Howard, R.P. Killmeyer, K.S. Rothenberger, A.V. Cugini, B.D. Morreale, R.M. Enick, F. Bustamante, J. Membrane Sci. 241, 207-218 (2004)

9. C. Wang, K. Bhatia, Electrochimica Acta. 49, 2333-2341 (2004)

10. M.A. Welayy, M.E. Gohary, R. Ammar, Alex. J Eng. 51, 69-75 (2012)

11. P. Giunta, M. Moreno, F. Mariño, N. Amadeo, M. Laborde, Chem Engg Technol. 35, 1-10 (2012) 